\title{
Narrative medicine in metastatic prostate cancer reveals ways to improve patient awareness \& quality of care
}

\author{
Giuseppe De Vincentis ${ }^{1}$, Fabio Monari ${ }^{2}$, Sergio Baldari ${ }^{3}$, Matteo Salgarello ${ }^{4}$, Viviana \\ Frantellizzi ${ }^{1}$, Elisabetta Salvi², Luigi Reale ${ }^{5}$, Silvia Napolitano*,5, Giario Conti6,7 \& Enrico \\ Cortesi $^{8}$ \\ ${ }^{1}$ Department of Radiological Sciences, Oncology \& Anatomo-Pathology, Sapienza - University of Rome, Rome, Italy \\ ${ }^{2}$ UO Metabolic Radiation Unit Bologna, Azienda Ospedaliero-Universitaria di Bologna Policlinico Sant'Orsola-Malpighi, \\ Emilia-Romagna, Italy \\ ${ }^{3}$ Department of Biomedical Sciences \& Morphological \& Functional Images, Università degli Studi di Messina, Messina, Italy \\ ${ }^{4}$ Division of Nuclear Medicine, Sacro Cuore - Don Calabria Hospital, Negraro (VR), Italy \\ ${ }^{5}$ ISTUD Foundation, Healthcare Area, Milan, Italy \\ ${ }^{6}$ Department of Urology, Sant'Anna Hospital, Como, Italy \\ ${ }^{7}$ Segretario Nazionale della Società Italiana di Urologia Oncologica (SIUrO), Bologna, Italy \\ ${ }^{8}$ Medical Oncology, Policlinico Umberto I, Sapienza, University of Rome, Rome, Italy \\ *Author for correspondence: Tel.: 0039388 8114177; snapolitano@istud.it
}

Aim: To describe the journey of patients with metastatic castration-resistant prostate cancer (mCRPC) in treatment with radium-223. Methods: A multiperspective analysis was performed using narrative medicine in four Italian centers. Results: The substantial impact of MCRPC on quality of life through all phases of the disease was described. After an initial lack of awareness of the disease or denial of its effects, symptoms of pain, fatigue and side effects often led to sadness, fear and loneliness. The majority underwent radium223 therapy positively, restoring their quality of life and routine activities. Conclusion: Using narrative medicine, the importance of a patient-centered approach in the pathway of care for patients with $\mathrm{mCRPC}$ through all the stages of the disease was highlighted.

First draft submitted: 20 April 2018; Accepted for publication: 30 May 2018; Published online:

15 June 2018

Keywords: metastatic castration-resistant prostate cancer • narrative medicine • quality of life

Prostate cancer is the most common cancer among men worldwide [1]. It is the third highest cause of cancer death in men, affecting 35,400 persons a year in Italy [2]. The incidence of this type of cancer has been increasing since the early 21 st century, likely because of the growing use of screening tests such as prostate-specific antigen (PSA). The survival rate is high, with $91 \%$ of patients still alive 5 years after diagnosis. However, $40 \%$ of men have metastases [2], which markedly decrease their overall quality of life $(\mathrm{QoL})$.

Prostate cancer most commonly metastasizes to the skeleton, leading to extremely fragile bones. Ra223 is indicated for the treatment of $\mathrm{mCRPC}$ patients with symptomatic bone metastases and no known visceral metastases, in progression after at least two prior lines of systemic therapy for mCRPC, or ineligible for any available systemic mCRPC treatment [3]. No evidence was published on possible barriers to the access to this treatment. This therapy was recently shown to increase overall survival rates [4]. Radium-223 acts as a calcium mimetic, complexing with hydroxyapatite and emitting alpha particles that break the double-stranded DNA, thus killing rapidly proliferating cancer cells in bone [5].

Care for patients with prostate cancer requires a multidisciplinary approach from diagnosis throughout the course of the disease [6]. National and international guidelines [7,8] suggest that close collaboration among various specialist physicians improves clinical management and therapeutic decision making, raising patients' awareness about available treatments and optimizing allocation of healthcare system resources [6-8]. The multidisciplinary healthcare team (MDT) should include urologists, radiologists, nuclear physicians, radiation oncologists, medical oncologists, psychologists and sex therapists. 
Even localized forms of prostate cancer and its treatment with drugs, surgery or other local therapy may cause symptoms such as the potential loss of urinary, bowel and sexual function; patients often report that these effects adversely affect QoL [9-12]. In advanced disease such as mCRPC, symptoms can be multiplied, coming directly from metastases or from toxicities of standard treatments, especially surgical or pharmacological androgen deprivation [1315]. These can all contribute to the deterioration of overall physical and functional well being, including the addition of further pain and fatigue [16]. Up to $50 \%$ of patients with advanced forms of prostate cancer are reported to be at high risk of psychological and emotional distress. In particular, anxiety about the progression of the disease, treatment efficacy, serial PSA values and chronic hormone administration can lead to depression, irritability and a sense of isolation [17].

Several studies have revealed that mCRPC affects not only the patient, but the entire family's routine. There may be particular stress on the partner who, along with the patient, faces significant psychological and sexual issues [18-21].

The WHO has recently underlined the importance of QoL research in guiding clinical practice and evidencebased research with the aim of improving the lives of people with chronic diseases [22]. Currently, medicine focuses on scientifically rigorous trials to develop specific protocols, according to the evidence-based medicine approach. In contrast, the ultimate aim of medical practice is always related to how patients live with their illness [23], a concept addressed in narrative-based medical research. "The innovation behind Narrative Medicine is thus having shifted the focus from the abstraction of objective numbers to the richness of information springing from contents of subjective written testimonies (personal considerations, interpretations, descriptions, insight, re-elaboration of events, contextualization of disease) and resources (health and QoL assessment questionnaires, diaries, surveys, etc.) the shift from quantitative analysis to qualitative analysis" [24]. Consequently, narrative medicine is an informative tool to explore and interpret information about the patient's experience of illness [25].

One of the pillars of narrative medicine is understanding the patient's personal experience and redesigning the pathway of care with a patient-centered view. This can be aided by tracking the course of events involved in managing the patient's care, focusing not just on the disease being treated, but also on the patient's experience of the entire process [26]. The 'patient journey' is defined as the experience and the processes the patient undergoes during the course of a disease and its treatment' [27]. Process mapping [26] of a patient journey is an approach already used for quality validation and is a common tool used to identify critical issues in the pathway of care [28]. By integrating clinical data with the actual lives of patients and their caregivers, including the emotional and psychological aspects of the journey, it can be quite informative [24].

The aim of this multiperspective project, involving patients, family caregivers and an MDT of professionals, was to outline and trace the organizational and procedural care map of patients with mCRPC being treated with radium-223, integrating clinical and narrative data to understand the patient journey.

\section{Methods}

The study consisted of an initial workshop followed by the subsequent execution of a narrative medicine project involving patients with $\mathrm{mCRPC}$ who were being treated with radium-223 in four Italian centers. The organizational and procedural pathway of care for MCRPC was presented as a flowchart by healthcare professionals. It was then integrated with patients' and caregivers' narratives using narrative medicine principles. Finally, the main outcomes from the integration of the narrative medicine analysis and the workshop report were commented on by the MDT member who developed the project.

\section{The organizational \& procedural pathway of care map}

The organizational and procedural pathway of care was mapped in the first step of the study in a 1-day national workshop [26] held by the ISTUD Foundation (Milan, Italy) and involving an MDT, including urologists, oncologists, radiotherapists, nuclear physicians and nurses, from the four Italian centers using radium-223. The centers, which are located across Italy, were the Sacro Cuore Hospital, Don Calabria of Negrar, the S Orsola Malpighi Hospital of Bologna, the Umberto I Policlinic Hospital of Rome and the G Martino Policlinic Hospital of Messina.

The physicians involved in the project participated in a kick-off meeting to plan the flowchart that would explore patients' perspectives rather than only following recommendations in guidelines [26]. They defined a set of major items of interest to be integrated with the patients' and caregivers' narratives. The pathway of care retraced each step from the discovery of metastases through the subsequent follow-up and treatment, with particular attention to logistic issues such as waiting lists [26,29]. 


\section{The qualitative \& narrative patient journey}

The field research collected narratives from patients and family members serving as caregivers about their personal view of the patient's journey. The focus in eliciting their experiences along the pathway of care was on the relational, emotional and affective aspects of the journey.

This second step of the study was conducted from October 2016 to July 2017 by ISTUD Foundation's researchers with expertise in narrative medicine methods. They were not members of the nuclear medicine center MDTs involved in treating the patients. This was in accordance with grounded theory so that patients' responses would not be influenced by having their own physicians interviewing them and in order to avoid researchers influence patients' answers since they were not coming from scientific or medical backgrounds [30]. Interviews were scheduled at the centers on random days and patients who had signed informed consent for the study were interviewed during routine visits. The interviews were conducted separately for patients and their relatives and then transcribed and analyzed using the narrative medicine approach [24] and NVivo software (London, UK).

All patients with a diagnosis of mCRPC with bone metastases who were being treated with radium-223 as targeted alpha therapy were invited to participate in and answer the survey. Caregivers actively caring for patients with $\mathrm{mCRPC}$ were included in the survey, independently from the grade of disease.

\section{Ethical considerations}

The project was approved by the Ethics Committees of the four centers involved in the project. The MDT of each center informed patients about the aim of the project, the confidential handling of narratives and the reporting of the results. Each participant gave written consent according to the Italian law on privacy and safeguarding of sensitive data (D.Lgs n196, 2003). The ISTUD researchers conducting the interviews were not allowed to access clinical data from any of the participants' medical records. All the interviews were conducted anonymously. The entire project was performed in accordance with the principles of the Declaration of Helsinki.

\section{Narrative medicine methods}

The interviews investigated the following items:

- Demographic information;

- Steps on the pathway of care: first signs and symptoms, medical visits, professional consultations, year of diagnosis, emotional impact of the diagnosis and related communication;

- Impact on QoL, in terms of relationships, emotions and daily activities;

- Previous treatment experience;

- Perception of therapies the patients were receiving, including a description of the experience, activities adversely or positively affected by the treatments and the specialists they saw;

- Future perspectives.

The interviewers were trained to use the most neutral terminology possible in order to avoid guiding the participants' answers, as stated in Greenhalgh's methodology [31]. Caregivers were interviewed with the same set of open questions, but they were also asked about their perceptions of the impact of the disease on the QoL of the entire family. They also described the elements of their informal caregiving.

All narratives were analyzed with QRS NVivo10 software (London, UK) to code and cluster items $[30,32]$. Findings from patients' and caregivers' testimonies were aggregated and reported as percentages.

\section{MDT members' points of view}

The MDTs who had participated in the design of the project and were caring for the patients who were interviewed, were asked for feedback on the main issues emerging from the integrated patient journey data provided by patients and caregivers. Their answers to open questions were collected online and included comments on the balance between length of life and QoL, the multidisciplinary approach, sexual function, previously administered therapies and evaluation of treatment with radium-223.

\section{Results}

The organizational \& procedural pathway of care for men with MCRPC

The workshop involving the MDTs allowed an understanding of the organizational and procedural pathway of care for mCRPC in Italy. The healthcare professionals participating identified three significant phases: communicating 
Table 1. Demographics.

\begin{tabular}{|c|c|c|}
\hline Socio-demographic data & $\%$ Patients $(n=47)$ & $\%$ Caregivers $(n=42)$ \\
\hline \multicolumn{3}{|l|}{ Average age } \\
\hline Years & $74(\min 58, \max 82)$ & $59(\min 32, \max 81)$ \\
\hline \multicolumn{3}{|l|}{ Educational level } \\
\hline Master's degree & $17(8)$ & $26(11)$ \\
\hline High school & $34(16)$ & $47(20)$ \\
\hline Secondary school & $22(11)$ & $24(10)$ \\
\hline Primary school & $27(13)$ & $3(1)$ \\
\hline \multicolumn{3}{|l|}{ Family status of patients } \\
\hline Married & $88(41)$ & - \\
\hline Father of children & $89(42)$ & - \\
\hline Not married & $12(6)$ & - \\
\hline Of which no children & $40(2)$ & - \\
\hline \multicolumn{3}{|l|}{ Family member (caregivers) } \\
\hline Wife & - & $57(24)$ \\
\hline Adult child & - & $35(15)$ \\
\hline Other & - & $8(3)$ \\
\hline \multicolumn{3}{|l|}{ Work status } \\
\hline Pensioners & $100(47)$ & $29(10)$ \\
\hline Of which still working & $12(6)$ & - \\
\hline Housewife/unemployed & - & $9(3)$ \\
\hline Self-employed & - & $17(6)$ \\
\hline Employed & - & $46(16)$ \\
\hline
\end{tabular}

the diagnosis of skeletal metastases; discussion of therapeutic strategy; and subsequent follow-up. These phases were propaedeutical to design the narrative interviews of the patients and their caregivers.

All phases of the map were agreed upon by the professionals participating in the workshop. For mCRPC in Italy in general, the pathway of care was similar across all Italian clinical practice, with the exception of targeted alpha therapy, with the MDTs highlighting barriers to access this treatment. They agreed that better access was required for all patients needing it. Thus, part of the narrative interviews focused on therapy access.

\section{The qualitative \& narrative patient journey of men with mCRPC Demographics}

In total, 50 patients and 50 caregivers were interviewed, with responses from 47 and 42, respectively, included in the narrative medicine analysis. The 11 excluded narratives were too short and lacking in data to be effectively analyzed. A total of ten online responses were provided by MDT members.

Demographic data of the participants (Table 1) reflected that of the general Italian population with prostate cancer and ISTAT data [2,33]. Although all the patients interviewed were receiving retirement pensions, $12 \%$ were still working, for example, as a private professional or a consultant or helping in their adult children's enterprises. Among caregivers, $57 \%$ were patients' wives. Of these, $61 \%$ were young women who were still working and caring for children.

\section{The patient journey}

Patients' average age was 65 years (44-80) at the time of the prostate carcinoma diagnosis. They had been living with the disease for a mean of 8.5 years (1-19) at the time of the interview. Compared with data reported in the literature that approximately $85 \%$ of cases of prostate cancer are diagnosed much more after the age of 65 , the participants in this study were younger when diagnosed [34].

Symptoms, such as urinary problems, were present in $77 \%$ of patients before the diagnosis of prostate cancer. The first sign of disease in 33\% of cases was detected through routine medical examination, such as the PSA test, while $7 \%$ presented with bone pain related to metastases. The total percentage was higher than $100 \%$ because several patients reported more than one first symptom. Urinary problems reported included frequency (18\%), hesitancy 
Table 2. The pathway of care.

Patients' memories of diagnosis communication

$23 \%$ bad memory "The whole world falling apart"; "It was a blow for me"; "In that moment, I felt discomfort because the Head of Urology communicated it to me with inhumanity and coldness. They told me they couldn't do nothing for me, so I had to be followed by an oncologists"; "One of the worst day of my life... my wife's question was 'Why it happens to us?"; "The first thing I thought was 'It is the end for me'; with this disease you could not live"

$9 \%$ positive memory "I never give up, I responded in a good way to it, I didn't cry for it"; "When they told me I have a carcinoma, it was as they said me I had a chronic otitis, I was calm"; "I wasn't worried, I took it lightly... I thought 'If it occur to others, it could occur also to me!"”

$68 \%$ don't remember

Caregivers' memories of diagnosis communication

"When they communicated us his diagnosis, I remembered very well that day in which he went to pick up his examination results, he said us to have a very high value of PSA [...]. For several time he denied all, so he was trying what were the correct therapy for him": "When they communicated his prostate cancer, ... I usually would like to know, even if I anxious but I never show it"

PSA: Prostate-specific antigen.

(11\%), hematuria $(7 \%)$ or dysuria $(2 \%)$. The first professionals involved in managing the prostate cancer were urologists for $55 \%$ of the respondents and general practitioners for $32 \%$. The remaining $13 \%$ of patients stated that they had their first medical consultation for prostate cancer with an orthopedic surgeon or hematologist, as their disease was already in a metastatic stage.

Although receiving a cancer diagnosis is usually a life-changing experience, the majority of participants completely removed that moment, appearing to have not been emotionally disturbed by the oncologic diagnosis. The narratives suggested that possible causes of this attitude were denial of the diagnosis or lack of awareness about the disease and its consequences. Among the men who answered the question about emotions at diagnosis (32\%), 23\% remembered being distressed at how the diagnosis was communicated to them, and only $9 \%$ had a positive memory of it (Table 2). Among family members, three did not want the patient to know the diagnosis to avoid causing him suffering or depression.

Because mCRPC is often fatal and yet one that negatively impacts QoL [1,2], the MDTs were asked their opinions on the balance between prolonging life and QoL (Appendix 2, Box 1). Professionals often spoke about the importance of self-determination for their patients, recognizing the need to share decision making with them before starting treatment.

\section{Impact on QoL}

\section{Emotions}

Although $90 \%$ of patients described their life as generally calm, substantial numbers reported worry (71\%) and sadness (64\%). Of those reporting sadness, $17 \%$ were considered to be clinically depressed, and three described a past episode of suicidal thoughts. Other emotions felt by participants included nervousness, irritability or a higher susceptibility (57\%) and a sense of uselessness (32\%) and loneliness (10\%) (Table 3).

\section{Sexual function}

Although in the majority of cases, both patients and their partners had agreed to surgery, the narratives revealed that the men were often not very aware of the risks and consequences of this choice, especially in regard to the potential for impotence. During the interview, $19 \%$ of patients preferred not to discuss sexual function at all, while $22 \%$ talked about it with resignation, reporting it as the biggest problem of their life. Only 33\% of patients reported having accepted their condition, using drugs to try to address erectile dysfunction and describing it as a new pattern of sexual functioning. Others (22\%) stated that they were trying further methods to solve this problem. Patients' negative or positive attitudes regarding sexual issues did not correlate with age; the average age of both those who accepted the situation and those who were still trying to find a solution was the same (75 years old). Partners had very different attitudes than the patients, accepting the situation with more serenity and calmness (Table 3). The MDT members were not only aware of their patients' difficulties with sexual functioning but were also actively seeking further help from psychologists and andrologists to address the problem (Appendix 3, Box 2). 
Table 3. The quality of life.

\begin{tabular}{|c|c|c|}
\hline Variables & Patients' narratives & Caregivers' narratives \\
\hline Emotions & $\begin{array}{l}\text { "The mood is always good, I always think about my granddaughters } \\
\text { and I'm happy"; "I'm overall calm. Today, they have calmed me. I have } \\
\text { the PSA value just a little high and so I am a bit worried. When I work I } \\
\text { feel well, I feel no loneliness, I'm still useful."; "I am never so deeply } \\
\text { calm. I never told about me, so today I was hardening, but I had } \\
\text { avoided showing it"; "When I deeply think about these things, I often } \\
\text { feel sad"; "I had a rope in my hands, I hung it around my neck.... } \\
\text { Then, I thought 'Oh my God, what am I doing???"' }\end{array}$ & $\begin{array}{l}\text { "He is very calm in dealing with this experience. He was totally aware } \\
\text { even from the beginning, he has a positive attitude."; "He sometimes } \\
\text { feel sad, his most frequent questions are 'How much time I will have } \\
\text { to live?' and I usually answer him he cannot make to me this kind of } \\
\text { joke!"; "I find him better, except for the mood. It makes him be } \\
\text { introvert and sad, while for the physical aspect he hasn't had any } \\
\text { physical deterioration"; "One morning, we were in the bed and he } \\
\text { said me: 'do you know... I thought to jump out of the window?"' }\end{array}$ \\
\hline Sexuality & $\begin{array}{l}\text { "I am very angry because they told me consequences on sexuality. } \\
\text { They said me "We will do injections and consequences will be past' but } \\
\text { this has disrupted my life"; "I would like to re-examine the sexuality } \\
\text { problem"; "My sexual activity is down to the zero... my wife that has } \\
\text { accepted the situation..."; "Concerning the sexuality life, I had to do } \\
\text { a pathway of care not so irrelevant for this, since the }[\ldots] \text { and }[. . .] \\
\text { (N/A names of drugs) don't work" }\end{array}$ & $\begin{array}{l}\text { "The sexual life is totally changed, although urologists had suggested } \\
\text { us to do injections with [...]. However, he didn't want it. I am a } \\
\text { woman, I don't suffer from it; while, as a man, it makes him feel sad."; } \\
\text { "Concerning the couple life, the lovemaking is possible in many } \\
\text { different ways and so, he is beginning to surrender himself, he has } \\
\text { understood how using his hands. Now, we have a different approach } \\
\text { to it... The sexuality is not the penetration! [...] At the beginning, my } \\
\text { husband was introvert, he didn't positively manage with the sexuality } \\
\text { and with his illness. When I was ill (breast tumor, A/N) I shared my } \\
\text { emotions, he doesn't" }\end{array}$ \\
\hline Caregiving & $\mathrm{N} / \mathrm{A}$ & $\begin{array}{l}\text { "I have problems in my kidneys, I cannot do heavy lifting. Yesterday, } \\
\text { he asked me if I could help him to stand up and to walk, but I cannot } \\
\text { do because of the pain in my kidneys. So, he was angry to me. For me, } \\
\text { he is lazy! He does not even reach out to take a glass of water! Not } \\
\text { even the telephone ringing! [...] When I have to go outside home for } \\
\text { some fees, I'll gladly do it, but every time he continues to ask me: 'Do } \\
\text { you really have to? How much time do you think to stay outside? But, } \\
\text { why do you have to?"; "I have loaded myself with depression, staying } \\
\text { close to him"; "I get help from a psychotherapist" }\end{array}$ \\
\hline
\end{tabular}

Activities

Difficulties described by participants included heavy lifting (63\%), short or long walks (26 and 43\%, respectively), everyday housekeeping activities (47\%), sleeping (66\%) and not being able to engage in hobbies they used to enjoy $(52 \%)$, especially sports. Furthermore, $62 \%$ of patients needed to nap or rest for at least several hours a day because of pain and fatigue. The narratives also described the patients' coping strategies, frequently including hobbies, taking care of grandchildren, gardening, working and leisure activities such as cinema and theatre.

Caregiving

In $61 \%$ of cases, the informal caregivers indicated that their support mainly involved activities outside the home, such as getting patients to the hospital for medical visits (35\%), going for commissions (such as going to the supermarket, to the post office or booking medical examinations ... etc.; 14\%) and accompanying them on walks (12\%). In $23 \%$ of cases, caregivers primarily provided company, as the patients were totally independent. However, $16 \%$ cared for a dependent patient requiring assistance with personal care such as washing and dressing. The main difficulties caregivers experienced were being outside the home for long periods (42\%), travelling (33\%), not being able to enjoy their own hobbies (24\%) and the need to take better care of themselves (26\%). In several cases, patients' relatives were themselves depressed or reported a need for psychological support (Table 3).

\section{Treatments}

Details of the radium-223 treatment all participants were receiving are shown in Figure 1.

Past and concurrent therapies most often cited in the narratives were chemotherapy (100\%), radiotherapy (23\%), hormone therapy (19\%) and combined treatment with zoledronic acid and denosumab (4\%). All patients were able to explain their chemotherapy and targeted alpha therapy in detail. For several participants, chemotherapy was currently effective against the carcinoma. Others had declined it, either because it was not effective in improving their condition or because they were worried about side effects (Table 4, Box 1). Several MDT members described shared decision making with the patient as the best strategy for choosing treatment, while others preferred a multidisciplinary approach to these decisions (Appendix 3, Box 3).

A total of $78 \%$ of patients and $60 \%$ of caregivers perceived the benefits of radium-223 as positive or very positive. (Figure 2). No patient had a negative opinion of this treatment. Between the third to fourth cycles, and the fifth to sixth cycles of administration, there was a 31\% increase in the patients' positive opinion (Figure 3). According to patients, the treatment reduced their pain (48\%), improved their energy and mood (33 and 12\%, respectively) 


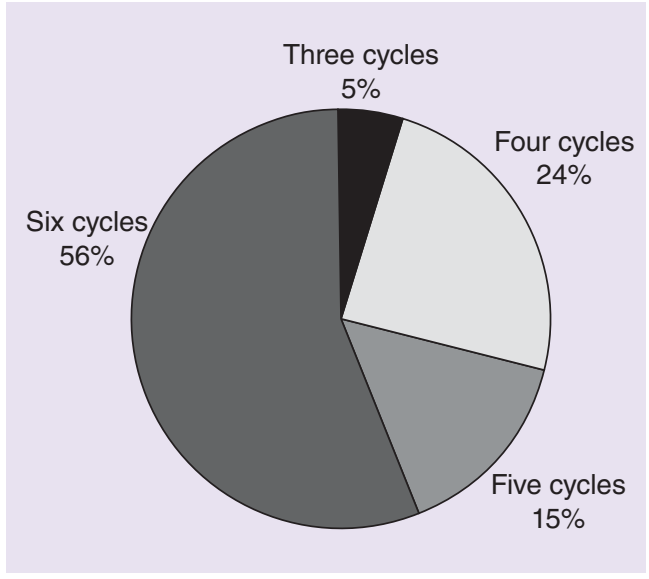

Figure 1. Number of cycles of targeted alpha therapy of patients participating.

\section{Table 4. Treatments.}

\begin{tabular}{|c|c|c|}
\hline $\begin{array}{l}\text { Perception of } \\
\text { treatments }\end{array}$ & Patients' narratives & Caregivers' narratives \\
\hline $\begin{array}{l}\text { Perception of } \\
\text { chemotherapy }\end{array}$ & $\begin{array}{l}\text { "Here, they immediately send me to do the chemotherapy, but they } \\
\text { couldn't administer me all the protocol because it made me feel too } \\
\text { bad"; "My fear is for my teeth. 2-3 years ago I had to spend a lot of } \\
\text { money because the chemotherapy had deteriorated them; so now I'm } \\
\text { afraid that a bad thing could happen to me!"; "I am angry because } \\
\text { the chemotherapy didn't work"; "If you give me chemotherapy, you } \\
\text { will kill me! With the chemo I am finished!"; "In the oncologic center I } \\
\text { am followed, I preferred to do the targeted alpha therapy and not the } \\
\text { chemotherapy, as suggested by... (I'm followed by two different } \\
\text { oncologic centers)." }\end{array}$ & $\begin{array}{l}\text { "We had already stopped, in December, the chemotherapy because he } \\
\text { had lost two feet nails; never lost his hair. He will never show it but he } \\
\text { is worried."; "Since he has started the chemotherapy, he feels better. } \\
\text { His mood is improved, his pain decreased, he sleeps better and he has } \\
\text { more appetite"; "... but anyhow, he is constricting himself, he is } \\
\text { boring, especially after the chemotherapy that is annoying him and } \\
\text { makes him feel tired and nervous." }\end{array}$ \\
\hline $\begin{array}{l}\text { Perception of } \\
\text { targeted alpha } \\
\text { therapy }\end{array}$ & $\begin{array}{l}\text { "I believed in this treatment, I had read up and I must say, I believed } \\
\text { so much that I joke about it with my friends: 'I'm becoming } \\
\text { radioactive!!'."; “I am reborn. The sleeping, I couldn't sleep because I } \\
\text { felt pain in each bone, it was efficacy especially in my legs and arms. } \\
\text { [...] Before it I couldn't do anything, no heavy lifting, for example, } \\
\text { when I had to go upstairs to reach my apartment, or when I have to } \\
\text { get out of the car I used to feel pain in my legs [... ]. The treatment I } \\
\text { have done for } 6 \text { months have saved my life!"; "I couldn't walk, the } \\
\text { healthcare local trust gave me wheelchair, I couldn't do more than ten } \\
\text { steps, I bought a portable chair because I used to be tired. The } \\
\text { treatment makes me feel very good, I have returned to walk, to sleep } \\
\text { again" }\end{array}$ & $\begin{array}{l}\text { "For me, it is a success, my father is well, for us the targeted therapy is } \\
\text { fantastic"; "The mood is skyrocketed after the treatments (N/A the } \\
\text { targeted alpha therapy). When you see the doctor satisfied of the } \\
\text { treatment, automatically also the mood of the patient is } \\
\text { skyrocketed."; "Since it has began the targeted therapy, it has } \\
\text { restored his appetite, made him increase in weight and feel more } \\
\text { relaxed"; "The mood is highly increased since his exam results are } \\
\text { good after the treatment he has done (N/A the targeted alpha } \\
\text { therapy). I'm seeing him highly better."; "With this treatment, he has } \\
\text { less pain in his bones, the blood test are improved, for example, in } \\
\text { terms of the hemoglobulin. This winter he was down, he couldn't } \\
\text { stand up; now, he is beginning to feel the wish of doing things; } \\
\text { before, he was always between the armchair and the bed." }\end{array}$ \\
\hline
\end{tabular}

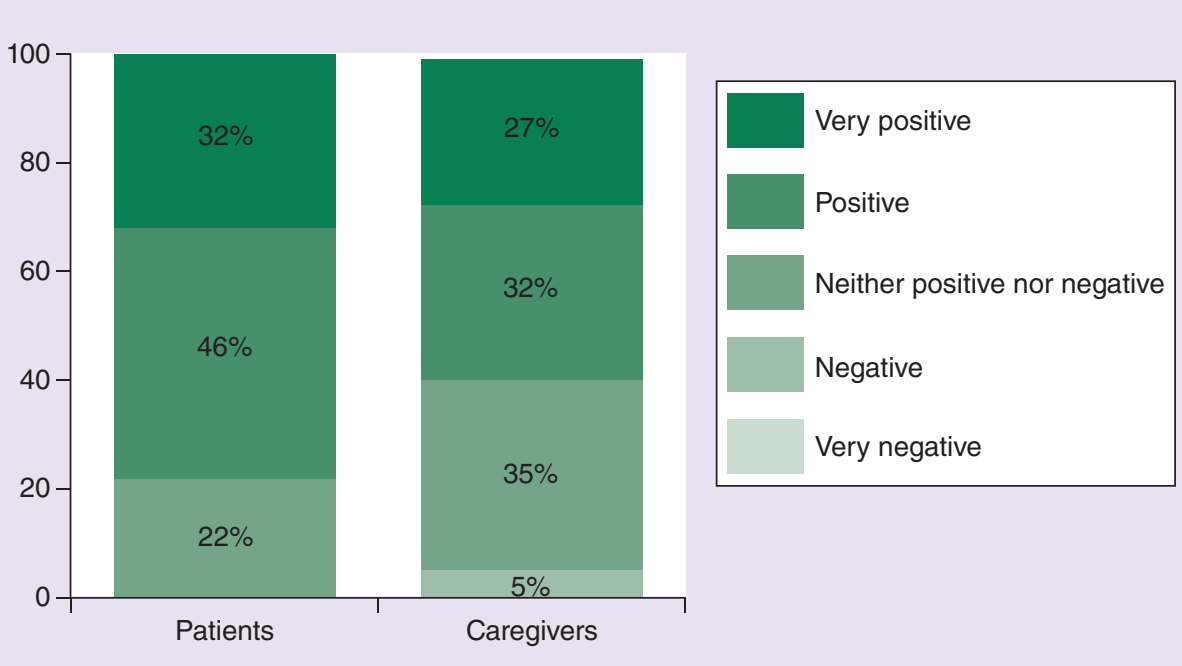

Figure 2. Patients' and caregivers' perception of the targeted alpha therapy. 


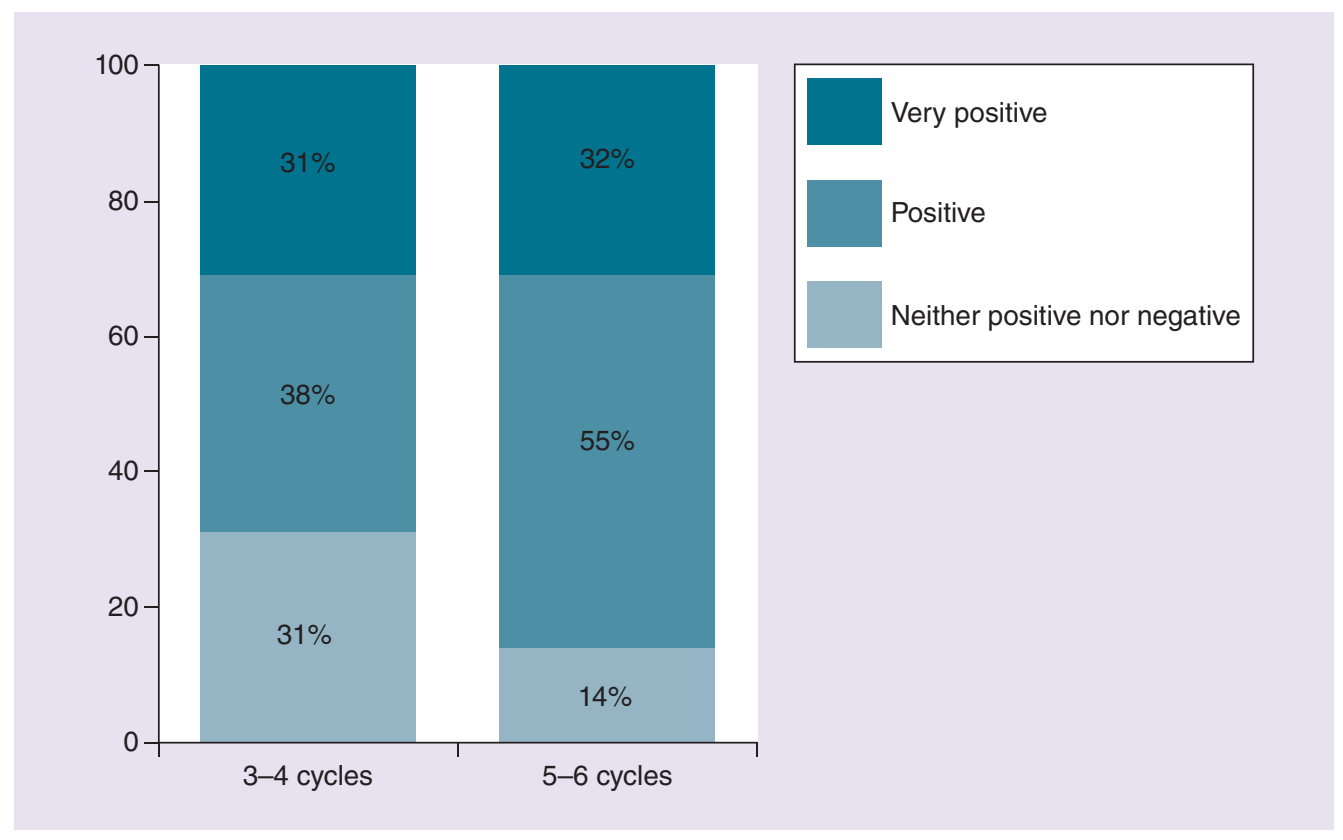

Figure 3. Patients' perception of the targeted alpha therapy through the cycles of treatments.

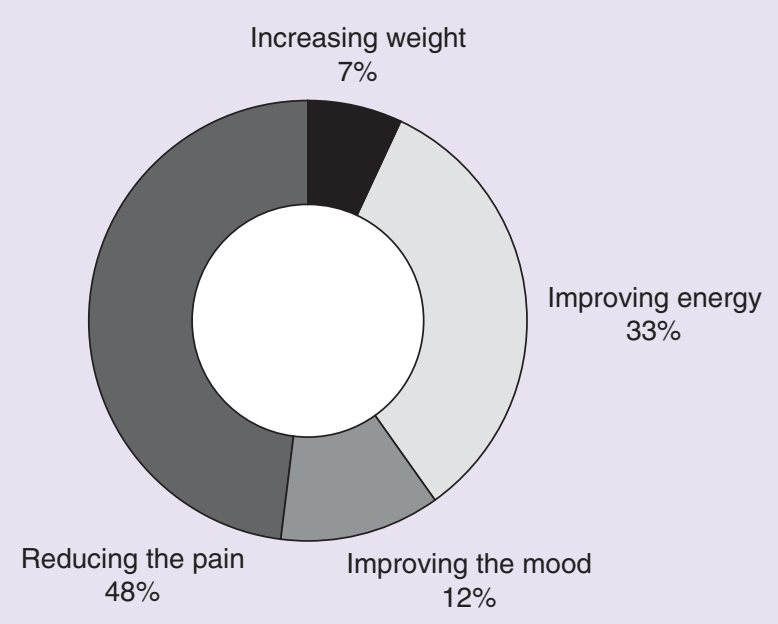

Figure 4. Patients' opinions on benefits of the radium-223.

and allowed them to gain weight (7\%) (Figure 4). Further, thanks to this treatment, the majority reported a return to past activities, such as walking, sleeping and heavy lifting, and a reduction in time spent sleeping or in bed. To the question "Are you worried about the use of therapeutic radiation?", no one declared feeling fear or anxiety as a result of the treatment. Indeed, in many cases, patients reported feeling lucky to have access to this treatment, often as a result of their own reading about it on online scientific sites. Although they experienced some difficulties in accessing targeted alpha therapy, the majority of patients viewed the treatments positively. Analysis of all the narratives revealed that in the majority of cases patients and caregivers described targeted alpha therapy using words and terms from the sphere of instilling 'hope' (as success, it saved my life, it increased his/her mood), since sufferers perceived themselves as 'reborn' because of this treatment, in terms of activities restored and mood increased (Table 4, Box 2). The MDT members' opinions about this treatment were also positive, since most were aware of the benefits it provided (Appendix 3, Box 4). The professionals also expressed positive opinions about the 
multidisciplinary approach in managing mCRPC and the creation of prostate cancer units in their centers in order to improve collaboration among different specialists (Appendix 3, Box 5).

\section{Participant future perspective}

Although the majority of participants expressed the desire for a beautiful holiday into the future, perhaps to escape from their painful situation, about $15 \%$ of narratives ended with a strong request to their physicians for more attention to the person and less to the disease. The majority of people interviewed (80\%) reported positive relationships with their clinicians, although $32 \%$ said they had previously experienced a difficult doctor-patient relationship. The other $20 \%$ of participants reported some difficulties with their physicians at the time of the interview. However, expressing their needs through the narrative medicine project was considered positive by $72 \%$ of participants. They perceived it as beneficial to themselves and thought it would be liberating for others with this diagnosis. Some (14\%) did not note any specific emotion or opinion about the narrative medicine approach $(14 \%)$, while $8 \%$ said talking about these issues was distressing; $6 \%$ reported that it made them reflect more on their situation.

\section{Discussion}

This is the first report of the patient journey of men with prostate cancer retraced through the narrative medicine approach, integrating patients' experiences by investigating both procedural and personal aspects of their care. This multiperspective study addressed three points of view: those of patients, caregivers and healthcare professionals.

One of the outcomes of this study concerned patients' lack of awareness of the implications of the disease in terms of what was involved in the pathway of care and the effects on QoL. This lack of awareness emerged from inquiries about emotions during the patient journey. In particular, $91 \%$ of patients either did not discuss their emotions at the time of diagnosis or reported having bad memories about it. Conversely, the female caregivers participating in the study had a different attitude about it than their husbands. In several cases, they themselves had been affected by female-specific cancers, such as breast cancer, and recalled their experiences with their own cancer in their narratives. Vraga et al. has recently demonstrated that women's cancers, such as breast cancer, tend to be overrepresented compared with men's cancers, specifically prostate cancer, in public campaigns on cancer awareness. They reported that breast cancer awareness activities have grown in prominence over the past 50 years, while mentions of prostate cancer were minimal on every platform they monitored [35]. The issue of sexual function was discussed by both patients and their partners. According to our findings, this issue seems not to be sufficiently explained to patients before surgery. Patients revealed that experiencing the side effects of standard treatment raised their awareness of the consequences of the disease, particularly in terms of the perceived impact on QoL, feelings of sadness or depression (64\%) and the pain and fatigue that often obligated them to renounce to many routine activities, all effects previously reported in the literature $[17,18]$.

Second, extending the qualitative investigation to caregivers confirmed the importance of their role as the patients dealt with the disease. Caregivers' narratives revealed a substantial, daily psychological burden as has been previously reported $[21,36,37]$. Participants' narratives were mainly stories about how mCRPC impacted their daily lives rather than focusing on the disease itself. It was also valuable to include MDT members' responses to the patients' and caregivers' views. The fundamental value of the doctor-patient relationship in promoting patient-centered care in oncology has been defined in the literature as a significant resource, especially for instilling hope and increasing patients' ability to cope with the disease [38,39]. Knowing not only a patient's clinical data but also the context of his entire family should deepen a clinician's understanding of what will help the patient feel better, a pillar of the narrative medicine approach as applied to the humanization of medical care. Consequently, key opinion leaders should promote adequate communication between Italian healthcare professionals and patients and their families. European guidelines stress the importance of a patient-centered approach in cancer care, highlighting the value of prostate cancer units [10], including recommendations about the role of psychologists. In fact, the MDT members participating in this study indicated the need for psychologists on their teams to help with communication about the side effects of treatments and to provide patient support. Patients reported a number of coping strategies that helped them overcome sadness and fear of the consequences of their illness, especially expressing gratitude to their family, particularly wives and grandchildren. According to the participants, access to the most recent treatments also helped them cope. In particular, the targeted alpha therapy was positively viewed by the participants, giving them an additional way to feel better as well as providing much needed hope. Although the most common limitations felt by patients were caused by the pain and the fatigue associated with the disease before the treatment, thanks to 
benefits of this therapy in reducing pain and increasing energy, their health status improved, they were able to gain weight and their perceived QoL and mood improved.

However, responses of MDT members at four specialized centers across Italy revealed heterogeneity in access to radium-223 therapy, as was also confirmed by many patients and caregivers. In particular, healthcare professionals agreed to the need for a uniform protocol for patient's access to radium-223, recommending that information be provided to Italian clinicians on the existence and benefits of this therapeutic option. Consequently, a deeper investigation of patient-perceived barriers in accessing this treatment should be undertaken. The promising results in our study can be further confirmed by further studies of larger cohorts in more treatment centers.

\section{Conclusion}

In conclusion, this investigation of the patient journey using narrative medicine has demonstrated this innovative approach to be a very informative tool in providing a deeper understanding of how patients and their families think, feel and act when facing mCRPC. Narrative medicine as a model of empathy, reflection and trust should be a competency of clinicians to serve patients with an oncological disease. Patients appreciated being listened to and were grateful to have access to targeted alpha therapy. The patients' journey along the pathway of care indicated that many had an initial lack of awareness of the disease, but their understanding increased as they began to experience side effects from standard treatments. In particular, both patients and their partners noted the impact of mCRPC on sexual functioning, highlighting the importance of including psychologists and sex therapists in MDTs. Healthcare professionals were concerned about barriers in accessing radium-223 treatment; these barriers must be overcome as patient access to the newest therapies, such as the targeted alpha therapy, was reported to be positive. Radium-223 therapy was perceived as effective and well tolerated by the majority of patients, that appreciated the ability of this therapy in improving QoL, thus confirming the recent clinical trial results [4]. However, this preliminary study did not delve into patients' personal way through the pathway of care by implementing patient's and caregiver's stories. Drafting an actionable summary from patients and caregivers to introduce in professionals clinical practice was not the aim of the present research study.

Our study confirms the value of a narrative medicine approach for evaluating the journey patients experience along the pathway of care, in particular providing an opportunity for them to express their needs and worries.

\section{Summary points}

- Patients experienced a substantial impact on quality of life, particularly in terms of patients' need to nap or rest for at least several hours a day and difficulties in walks because of bone pain and fatigue.

- Caregivers experienced a substantial psychological burden because of assisting their relative with metastatic castration-resistant prostate cancer.

- The participants' perception of radium-223 was overall positive, since it was considered by the majority helping to restore patients' daily activities and to improve quality of life.

- The memory of emotions at the diagnosis was removed by the majority of patients, revealing an initial lack of awareness by them.

- Consequences of standard treatments on sexual function were initially not completely clear to patients.

- Interviewed multidisciplinary healthcare team professionals requested for a more effective multidisciplinary approach since the moment of the diagnosis, to the living with prostate cancer, to the follow-up, especially through improving the role for psychologists.

- Interviewed multidisciplinary healthcare team professionals, confirmed by patients and caregivers, testified barriers in accessing radium-223, explaining the actual heterogeneity in the pathway of care of metastatic castration-resistant prostate cancer in the Italian setting.

Supplementary data

To view the supplementary data that accompany this paper please visit the journal website at: www.futuremedicine.com/doi/suppl/10.2217/fon-2018-0318

\section{Acknowledgements}

The authors wish to thank to all patients and families that decided to participate in the project. Particular acknowledgements to MG Marini, A Cappuccio, V Gatti and P Chesi, researchers of the Healthcare Area of ISTUD Foundation. 


\section{Authors' contributions}

G De Vincentis, F Monari, S Baldari, M Salgarello, V Frantellizzi, E Salvi, L Reale, G Conti and E Cortesi substantially contributed to the conception or design of the work; or the acquisition, analysis or interpretation of data for the work. G De Vincentis, F Monari, S Baldari, M Salgarello, V Frantellizzi, E Salvi, L Reale, S Napolitano, G Conti and E Cortesi drafted the work or revised it critically for important intellectual content. G De Vincentis, F Monari, S Baldari, M Salgarello, V Frantellizzi, E Salvi, L Reale, S Napolitano, G Conti and E Cortesi gave final approval of the version to be published. G De Vincentis, F Monari, S Baldari, M Salgarello, V Frantellizzi, E Salvi, L Reale, S Napolitano, G Conti and E Cortesi agreed to be accountable for all aspects of the work in ensuring that questions related to the accuracy or integrity of any part of the work are appropriately investigated and resolved.

Financial \& competing interests disclosure

This study was performed with the unconditional contribution of Bayer spa. The authors have no other relevant affiliations or financial involvement with any organization or entity with a financial interest in or financial conflict with the subject matter or materials discussed in the manuscript apart from those disclosed.

\section{Funded writing assistance}

Authors are also grateful to Enago (Crimson Interactive, Inc.) for the revision of English, and to corresponding author S Napolitano for writing the article. They are grateful to the ISTUF Foundation for the funding of the English review.

\section{Ethical conduct of research}

The project was approved by the Ethics Committees of the four centers involved in the project. Each participant gave written consent according to the Italian law on privacy and safeguarding of sensitive data (D.Lgs n196, 2003). The entire project was performed in accordance with the principles of the Declaration of Helsinki.

\section{References}

Papers of special note have been highlighted as: $\bullet$ of interest; $\bullet \bullet$ of considerable interest

1. Siegel RL, Miller KD, Jemal A. Cancer statistics, 2017. CA Cancer J. Clin. 67, 7-30 (2017).

2. Linee guida Aiom Carcinoma della prostata (2017). www.aiom.it/C_Common/Download.asp?file=/\$Site\$/files/doc/LG/2017_LGAIOM_Prostata.pdf

3. European Medicines Agency. Xofigo, INN- radium-223 dichloride. www.ema.europa.eu/documents/product-information/xofigo-epar-product-information_en.pdf

4. Parker C, Heinrich D, O'Sullivan JM et al. Overall survival benefit of radium-223 chloride (Alpharadin ${ }^{T M}$ ) in the treatment of patients with symptomatic bone metastases in castration-resistant prostate cancer (CRPC): a Phase III randomized trial (ALSYMPCA). Eur. J. Cancer 47(Suppl. 2), 3 (2011).

5. Lewis B, Chalhoub E, Sartor O. Radium-223 in bone-metastatic prostate cancer: current data and future perspects. Oncology (Willinston Park) 29, 483-488 (2015).

6. Wong WW, Anderson EM, Mohammadi H et al. Factors associated with survival following radium-223 treatment for metastatic castration-resistant prostate cancer. Clin. Genitourin. Cancer 15(6), e969-e975 (2017).

7. McGann S, Horton ER. Radium-223 dichloride: a novel treatment option for castration-resistant prostate cancer patients with symptomatic bone metastases. Ann. Pharmacother. 49(4), 469-476 (2015).

8. Sciarra A, Gentile V, Panebianco V. Multidisciplinary management of prostate cancer: how and why. Am. J. Clin. Exp. Urol. 1(1), 12-17 (2013).

9. Mosel D 1, Shamp MJ. Enhancing quality improvement team effectiveness. Qual. Manag. Health Care 1(2), 47-57 (1993).

10. Valdagni R, Van Poppel H, Aitchison M et al. Prostate cancer unit initiative in Europe: a position paper by the European School of Oncology. Crit. Rev. Oncol. Hematol. 95(2), 133-143 (2015).

\section{- Reference of interest to better understand items investigated in the study.}

11. Potosky AL, Legler J, Albertsen PC et al. Health outcomes after prostatectomy or radiotherapy for prostate cancer: results from the prostate cancer outcomes study. J. Natl Cancer Inst. 92, 1582-1592 (2000).

12. Sanda MG, Dunn RL, Michalski J et al. Quality of life and satisfaction with outcome among prostate-cancer survivors. N. Engl. J. Med. 358, 1250-1261 (2008).

13. Trost LW, Serefoglu E, Gokce A et al. Androgen deprivation therapy impact on quality of life and cardiovascular health, monitoring therapeutic replacement. J. Sex Med. 10(Suppl. 1), 84-101 (2013).

14. Elliott S, Latini DM, Walker LM et al. Androgen deprivation therapy for prostate cancer: recommendations to improve patient and partner quality of life. J. Sex Med. 7(9), 2996-3010 (2010). 


\section{- Reference of interest to better understand items investigated in the study.}

15. Protopapa E, van der Meulen J, Moore CM et al. Patient-reported outcome (PRO) questionnaires for men who have radical surgery for prostate cancer: a conceptual review of existing instruments. BJU Int. 120(4), 468-481 (2017).

16. Madalinska JB, Essink-Bot M-L, de Koning HJ et al. Health-related quality-of-life effects of radical prostatectomy and primary radiotherapy for screen detected or clinically diagnosed localized prostate cancer. J. Clin. Oncol. 19, 1619-1628 (2001).

17. Litwin MS, Hays RD, Fink A et al. Quality-of-life outcomes in men treated for localized prostate cancer. JAMA 273, 129-135 (1995).

18. Cella D, Li S, Li T et al. Repeated measures analysis of patient-reported outcomes in prostate cancer after abiraterone acetate. J. Community Support Oncol. 14(4) 148-54 (2016).

19. De Sousa A, Sonavane S, Mehta J. Psychological aspects of prostate cancer: a clinical review. Prostate Cancer Prostatic Dis. 15(2), 120-127 (2012).

20. Wittmann D, Carolan M, Given B et al. What couples say about their recovery of sexual intimacy after prostatectomy: toward the development of a conceptual model of couples' sexual recovery after surgery for prostate cancer. J. Sex Med. 12(2), 494-504 (2015).

21. Chisholm KE, McCabe MP, Wootten AC et al. Review: psychosocial interventions addressing sexual or relationship functioning in men with prostate cancer. J. Sex Med. 9(5), 1246-1260 (2012).

22. Greenhalgh T. Cultural contexts of health: the use of narrative research in the health sector. Copenhagen: WHO Regional Office for Europe; (2016) (Health Evidence Network (HEN) synthesis report 49). www.euro.who.int/__data/assets/pdf_file/0004/317623/HEN-synthesis-report-49.pdf

-. Reference of considerable interest to understand the importance of narrative medicine in Quality of Life research.

23. Greenhalgh T. Narrative based medicine: narrative based medicine in an evidence based world. BMJ 318(7179), 323-325 (1999).

24. Marini MG. Narrative Medicine: Bridging the Gap Between Evidence-Based Care and Medical Humanities. Springer International Publishing, NY, USA (2016).

25. Charon R. Narrative Medicine: Honouring the Story of Illness. Oxford University Press, NY, USA (2006).

26. Trebble TM, Hansi N, Hydes T et al. Process mapping the patient journey: an introduction. BMJ 341, c4078 (2010).

27. Manchaiah VK, Stephens D, Meredith R. The patient journey of adults with hearing impairment; the patients' views. Clin. Otolaryngol. 36(3), 227-234 (2011).

28. Chisholm N, Gillett G. The patient's journey: living with locked-in syndrome. BMJ 331(7508), 94-97 (2005).

29. Barach P, Johnson JK. Understanding the complexity of redesigning care around the clinical microsystem. Qual. Saf. Health Care 15(Suppl. 1), i10-i16 (2006).

30. Corbin J, Strauss A. Basics of qualitative research. In: Techniques and Procedures for Developing Grounded Theory. SAGE Publications (2015).

31. Greenhalgh T, Hurwitz B. Why study narrative? In: Narrative Based Medicine: Dialogue and Discourse in Clinical Practise. Greenhalgh T, Hurwitz B (Eds). BMJ Publishing Group, London, UK (1998).

32. Creswell JW. Research Design: Qualitative, Quantitative, and Mixed Methods Approaches. SAGE Publications, CA, USA (2014).

33. ISTAT Popolazione Residente al 1 gennaio (2017) http://dati.istat.it/Index.aspx?DataSetCode=DCIS_POPRES1\#.

34. Patel AR, Klein EA. Risk factors for prostate cancer. Nat. Clin. Pract. Urol. 6(2), 87-95 (2009).

35. Vraga EK, Stefanidis A, Lamprianidis G et al. Cancer and social media: a comparison of traffic about breast cancer, prostate cancer, and other reproductive cancers on Twitter and Instagram. J. Health Commun. 23(2), 181-189 (2018).

36. Kunkel EJ, Myers RE, Lartey PL et al. Communicating effectively with the patient and family about treatment options for prostate cancer. Semin. Urol. Oncol. 8, 233-240 (2000).

37. Northouse LL, Mood DW, Montie JE et al. Living with prostate cancer: patients' and spouses' psychosocial status and quality of life. J. Clin. Oncol. 25, 4171-4177 (2007).

38. Proserpio T, Ferrari A, Lo Vullo S et al. Hope in cancer patients: the relational domain as a crucial factor. Tumori 101(4), 447-454 (2015)

39. Werner A, Steihaug S. Conveying hope in consultations with patients with life-threatening diseases: the balance between supporting and challenging the patient. Scand. J. Prim. Health Care 35(2),143-152 (2017). 